\title{
BEBÊS E CRIANÇAS BEM PEQUENAS NO DEBATE SOBRE CULTURA INFANTIL
}

Andrea Braga Moruzzi ${ }^{i}$

Giovana Alonso ii

\begin{abstract}
Resumo: Este artigo busca apresentar o modo pela qual os bebês e as crianças bem pequenasiii estão inseridos no debate acadêmico sobre cultura e cultura infantil. Sob inspiração cartográfica e permeando o campo dos Estudos da Infância, apresenta-se o recorte de uma pesquisa que vem sendo desenvolvida junto à um Programa de Pós-Graduação em Educação. Dentre seus resultados, comenta-se o modo como estes sujeitos são caracterizados pela subalternidade em perspectivas e estudos que não consideram suas agências e sua potência criadora, assim como suas linguagens e formas específicas de produzir cultura. Outros olhares sobre a infância tornamse emergentes neste cenário.
\end{abstract}

Palavras-chave: Bebês; Crianças bem pequenas; Subalternidade; Cultura infantil; Sociologia da Infância.

\section{BABIES AND VERY SMALL CHILDREN IN THE CHILD CULTURE DEBATE}

\begin{abstract}
This article seeks to present the way in which babies and very young children are inserted in the academic debate about children's culture and culture. Under cartographic inspiration and permeating the field of Childhood Studies, there is an outline of a research that has been developed in conjunction with a Postgraduate Program in Education. Among its results, we comment on the way in which these subjects are characterized by subalternity in perspectives and studies that do not consider their agencies and their creative power, as well as their languages and specific ways of producing culture. Other views on childhood are emerging in this scenario.
\end{abstract}

Keywords: Babies; Very small children; Subordination; Children's culture; Sociology of Childhood.

\section{Introduzindo o debate}

"Penso, logo existo". Esta é a máxima da razão expressa por Descartes no século XVII. Pilar da cultura ocidental, o racionalismo baseia-se na universalização do pensamento, estruturando um tipo de epistemologia e inaugurando uma ontologia que tem o norte como orientação e a Europa como centro. O objeto de Descartes é o conhecimento praticado com base num método de pensamento solitário, atividade esta que desemboca no conhecimento do ser.

2020 Bargas; Ayoub; Assaritti, Scarazzatto, Assis. Este é um artigo de acesso aberto distribuído sob os termos da Licença Creative Commons Atribuição Não ComercialCompartilha Igual (CC BY-NC-4.0), que permite uso, distribuição e reprodução para fins não comerciais, com a citação dos autores e da fonte original e sob a mesma licença 
Trata-se de uma ciência baseada na verdade e na certeza, em que o homem - masculino, adulto, branco e da elite - é quem a constrói.

O sistema cartesiano se apoia na consideração de que a natureza é para o homem objeto de dominação. Tomando a Europa como centro e o homem, branco, adulto e de elite como modelo, tem-se por consequência, em detrimento deste eu, a produção do outro: aquele que não pensa como tal, aquele que não fala como tal, aquele que não produz conhecimento como tal, aquele que não possui alma. Este outro nega tudo aquilo que o eu - self - representa, sem identificação e sem igualdade a ele. Sem intelecto e sem razão, este outro vai sendo igualado aos animais e à própria natureza, conduzindo e suportando o processo colonizador (DESCARTES, 1983)

Este artigo olha para a produção destes sujeitos "outros" - os sujeitos subalternos, aqueles que se afastam do centro de referência e uma vez afastando-se deixam de ser ouvidos. A criança é subalternizada, assim como o são a mulher, o(a) negro(a), o(a) pobre, o(a) homossexual, o(a) indígena etc. A criança é subalternizada por distanciar-se em corpo e expressão do adulto. A criança é subalternizada por não se comunicar tal como o adulto, por não falar tal como o adulto, por não pensar tal como o adulto, por não comer tal como o adulto, por não agir tal como o adulto e por não garantir, tal como ele o faz, que a lógica capitalista da produtividade se mantenha constante. A criança é colocada à margem, é perifericamente excluída das relações, é epistemologicamente silenciada ao basear-se a sua educação e sua socialização em determinações que não consideram sua potência, sua agência, seu protagonismo, sua interferência, os relacionamentos que estabelece e a sua produção no mundo. Pelo contrário, as referências para sua educação e socialização invocam imperativos da passividade, da quietude, da retaguarda, esquadrinhamento, de governança e de proteção, proteção que por vezes é mascarada pelo abuso de poder.

Os estudos subalternos emergem nos anos de 1980 com o indiano Ranajit Guha, intervindo na historiografia sul-asiática, possibilitando a crítica ao pós-colonialismo. Stuart Hall (2003) interroga o uso do sufixo pós, na interpretativa de que o período colonial não deixou de ser, mas se mantém com suas forças e estratégias nas relações interpessoais na contemporaneidade. Os estudos pós-coloniais questionam as disposições e relacionamentos presentes no mundo contemporâneo e globalizado, refletindo os impactos dos processos colonizadores nas experiências individuais e também grupais. O pós-colonial permite a releitura de modelos de caráter hegemônico e a abertura para outras construções teóricas e conceituais. A 


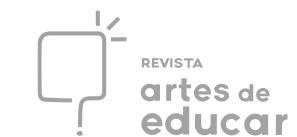

problemática é caracterizada pela consideração de um único modelo em detrimento de uma infinidade de possibilidades humanas, sociais e culturais. É neste sentido que o pós-colonial considera a construção de outras narrativas e a constituição de outros conceitos, reverberando sobre como determinadas ideias e concepções tomam corpo ao serem utilizados de maneira canônica por suas respectivas áreas e campos do conhecimento.

É no movimento de compreender que existe uma narrativa da infância e da criança que precisa ser recontada, a partir de outros posicionamentos, de outros interesses e de outras vozes que este texto se insere. As crianças - incluindo os bebês e as crianças bem pequenas - são protagonistas de suas vidas e de suas experiências e tem muito a falar - com outros modos de expressão e com outras linguagens - sobre como descobrem o mundo, inventam as relações e se reconhecem nos desafios e nas conquistas diárias.

As crianças possuem cultura e há um modo muito específico de percebê-las em produção e atividade. Para o campo dos Estudos Sociais da Infância, as crianças são sujeitos sociais e de direitos e apropriam-se do mundo de modo criativo, produtivo e interpretativo. Reproduzem o mundo adulto em que se inserem, mas fazem uso dele a partir de suas próprias referências, reinventando maneiras de agir, de se portar, de se relacionar e de construir histórias sobre si mesmas. Considerar que há uma cultura infantil sendo produzida pelas crianças, nas relações interpessoais com seus pares e em seus grupos, oportuniza a visibilidade de suas diferentes linguagens. Com base na compreensão de que as crianças se expressam por meio de diferentes linguagens, comunicam-se entre si e estabelecem relações de interação também com os adultos permite tornar reconhecida sua potência, sua inventividade ou mesmo sua intempestividade (ABRAMOWICZ; LEVCOVITZ; RODRIGUES, 2009). As crianças falam, mas nem sempre as escutamos. Uma nova epistemologia para a infância, baseada na escuta e na reinvenção das formas de escutar as crianças se faz necessária. É neste ponto que inicia-se a discussão.

\section{Da infância subalterna à agência infantil}

Para Descartes, segundo Badinter (1985), o erro do homem foi ter sido criança, este ser sem discernimento, sem razão e sem cultura. Nesta medida, historicamente investiu-se na tentativa de tirar a humanidade desta condição de imbecilidade, desta condição em que não se sabe falar, agir, pensar, comer, produzir. A educação, desde que reconhece o sentimento de infância e com ele a necessidade de conduzir práticas e modos específicos de socialização desses

Revista Interinstitucional Artes de Educar. Rio de Janeiro, V. 6, N.2- pág. 653-675 maio-agosto de 2020: "Bebês e crianças: cultura, linguagem e políticas" 
sujeitos, garante que as crianças sejam interpretadas em especificidade, mas não lhes retira o caráter negativo que os discursos religiosos, filosóficos e médicos construíram historicamente (BADINTER, 1985).

O sentimento de infância não reverbera à criança sentimentos de afeição. Pelo contrário, apesar da especificidade garantida com o surgimento de tal sentimento, verifica-se que a condição da criança se perpetua na negatividade. A criança que amedronta, a criança que é estorvo, que é incompleta e que é negativa vai caracterizando determinados discursos religiosos, filosóficos e políticos - sobre as crianças. Para Badinter (1985), uma sociedade que tem medo do amor baseia-se na rigorosidade e na punição. As instituições de cuidado ${ }^{\text {iv }}$ para com a criança, recebendo denominações como asilos, creches, jardins de infância e pré-escola, surgem com suas medidas e suas respostas às necessidades infantis, tais como as famílias nucleares, as escolas e a própria pedagogia.

Uma infância moderna torna-se hegemônica ao passo em que modelada pelos referentes sociais europeus. A ideia de uma infância branca e burguesa, que precisa ser cuidada, protegida, estudada, medicalizada, padronizada, governada e esquadrinhada se expande e se constitui globalmente, ao passo em que a cultura europeia se torna globalizada em decorrência dos processos de colonização do Ocidente. Os processos de colonização dos povos ocidentais não apenas negam as formas de vida e as configurações sociais já existentes nos territórios ocupados, como também impõe uma determinada cultura considerada dominante em razão delas, tornandoas menores, subalternas e marginalizadas. A obra de Spivak (2010) é elucidativa no que diz respeito ao modo como os povos colonizados e os indivíduos que nasceram, cresceram e viveram em sociedades colonizadas se inserem em processos de dominação.

Spivak (2010) narra a história de mulheres que silenciadas por discursos de opressão e dominação, são distanciadas de seus direitos fundamentais. Os estudos subalternos, movimento teórico em que se insere, está interessado na voz do "outro", este outro construído, compreendido e historicamente inferiorizado em relação ao "eu", este "eu" que é branco, masculino, adulto, elitizado e cristão. Para esta autora, não se trata de substituir a figura do colonizador invertendo as lógicas de dominação. Trata-se de assumir novas posturas sobre as histórias que são narradas num processo que busca encontrar as vozes perdidas dos sujeitos subalternizados. O ocidente, em dimensões culturais e territoriais, é subalterno e a dominação de seus sujeitos se dá, dentre outras maneiras, por meio da fala. Nesse sentido, compreende-se como soberanos o pesquisador, o professor, o adulto e intelectual, enquanto os subalternos são 
compreendidos como as crianças, as mulheres, os negros e os pobres. O sujeito subalterno é visto pela autora como um efeito do discurso dominante, marcado por sistemas repressores.

A atenção está no fato de que a teoria - eurocêntrica, produzida por homens e brancos não representa, de forma alguma, os grupos oprimidos. Representação é conceituada como a atitude de "falar por". No caso dos sujeitos subalternos, há representações sendo realizadas sobre eles sem que os mesmos sejam escutados, ouvidos, vistos e lidos, como a própria autora menciona. O sujeito fala por si e possui capacidade de escolha. $\mathrm{O}$ subalterno, pelo contrário, como aquele que não fala, não é considerado sujeito. O subalterno não fala, ao passo que tem quem fale por ele, quem o guie e quem o represente (SPIVAK, 2010).

A subalternidade trata de um projeto de inferiorização de um tipo de ser humano em razão da reafirmação de um outro tipo de ser humano por vias da opressão. Spivak (2010) interessa-se em medir os silêncios e revelar aquilo que todos se recusam a dizer e ouvir. Medir silêncios é para a autora processo de desaprendizagem, de acessar outra via de pensamento contrária ao comum e dominante.

O projeto de colonização é eterno e com base numa perspectiva foucaultiana, gênero, sexualidade, idade e classe social são vias para realizá-lo. Para Foucault (apud Spivak, 2010), as relações de poder - dos séculos XVII e XVIII - eram independentes das relações de soberania, porém dependentes das relações que os indivíduos mantinham com seus corpos. Com base em técnicas e procedimentos específicos, o poder age por intermédio do gerenciamento dos espaços, pelo aperfeiçoamento das administrações (asilos, escolas, instituições de reclusão como um todo) e considerando a periferia em termo dos loucos, dos prisioneiros e das crianças. Estes indivíduos, colocados a margem, traduzem-se em vias para atuar e atingir o restante da sociedade, construindo a narrativa do normal. O subalterno não pode falar. Não há valor algum atribuído à "mulher" como um item respeitoso nas listas de prioridades globais. A representação não definhou. A mulher intelectual como uma intelectual tem uma tarefa circunscrita que ela não deve rejeitar com um floreio (SPIVAK, 2010, p. 165). É neste aspecto que ignorar o subalterno é corroborar com um projeto imperialista e é na mesma medida que lutas feministas, as lutas identitárias, as mulheres no mercado de trabalho, as professoras, as militantes e todas as formas de resistência se colocam em guerra com as relações de dominação na qual estão inseridas as mulheres, os pobres, os negros, as crianças, os deficientes, os indígenas, os homossexuais, entre outros grupos.

Revista Interinstitucional Artes de Educar. Rio de Janeiro, V. 6, N.2- pág. 653-675 maio-agosto de 2020: "Bebês e crianças: cultura, linguagem e politicas" 
Para os estudos pós-coloniais a subalternidade não é fixa, tendo-se que levar em conta diferentes variáveis e pontos de localização para identificá-la. É nesta medida que se reconhece que toda condição de desigualdade possui espaço para agência e que mesmo no interior de uma situação de opressão é possível que os indivíduos se agenciem, tomando por exemplo as mulheres que rompem com situações de opressão e tornam possível que suas vozes sejam ouvidas. Os espaços de vocalização estão se ampliando e é esta potência pretendida para que a posição de subalternidade de determinados indivíduos se altere.

A Sociologia da Infância caminha tangencialmente aos estudos pós-coloniais, inserindo em suas temáticas a condição da criança na sociedade, os espaços em que se insere, compactuando com referenciais que reconhecem a agência das crianças, movimentando outras perspectivas teóricas que retiram as crianças da invisibilidade, fazendo uso de outras metodologias de pesquisa que escutam as vozes das crianças, visualizando suas participações, seus potenciais criativos e de inventividade e suas possibilidades de escolha, interessando-se pela educação, pela socialização e pela cultura das crianças. Essa invisibilidade nos estudos da infância se dá de forma incipiente sobre os bebês, que pouco aparecem nos textos oficiais e nos discursos pedagógicos (GOBBATO, BARBOSA, 2017). A Sociologia da infância é uma área em construção (ABRAMOWICZ, OLIVEIRA, 2010) e inserida nos Estudos da Infância, compartilha dos objetivos e pressupostos de outras áreas interessadas nas crianças e em suas infâncias ${ }^{\mathrm{v}}$.

A abertura para compreender a infância e as infâncias - no plural, já que as crianças são muitas e as infâncias são múltiplas - é o movimento da Sociologia da Infância ao colocar em pauta, dentre outros, os temas da autoria e da agência infantil. As crianças são atores sociais e de direito (NASCIMENTO, 2011). Mas o que isso significa? Significa terem seu papel ativo na sociedade respeitado, participando dos processos de tomada de decisão e colaborando na manutenção da cultura. Quinteiro (2002) reconhece as crianças como atores sociais no interior das escolas públicas, mas também no interior de suas próprias famílias. As crianças produzem sentido para o mundo e compartilham com os adultos seus modos de ser e de se relacionar (BARBOSA, 2014). A Sociologia da Infância torna emergente um novo olhar que possa considerar a criança em tudo que diz com suas diferentes linguagens (QUINTEIRO, 2002). Nascimento (2010) anunciava a invisibilidade da criança ao denunciar o esvaziamento de pesquisas sobre e em creches, indicando o desinteresse e a desconsideração acerca dos direitos das crianças, neste caso, o direito a educação.

Revista Interinstitucional Artes de Educar. Rio de Janeiro, V. 6, N.2-pág. 653-675 maio-agosto de 2020: "Bebês e crianças: cultura, linguagem e políticas" 
Tebet (2013) afirma a agência das crianças e a infância como uma construção social como marca das perspectivas sociológicas sobre a infância. Essa agência é atravessada pela posição que as crianças ocupam em determinadas sociedades e em determinados grupos, sendo, portanto, mutável e flexível. O termo agency interroga as relações sociais das crianças e a produção de suas culturas, possibilitando perceber que há uma cultura particular da qual as crianças compartilham. Isso não quer dizer que as crianças vivem em um mundo distinto ao mundo dos adultos, mas permite caracterizar as relações infantis em especificidade e contexto, em formas de expressão diferenciadas, em prerrogativas que invocam a determinação dos papéis desses sujeitos - ativo, criativo e protagonizado. Agency e sua tradução agência significam potencial de ação.

É na medida em que se compreende a infância como construção e como estrutura social e se reconhece o papel das crianças nesta mesma estrutura, assim como o papel das crianças pequenas e dos bebês, que delineia-se a tentativa de compreendê-los na dinâmica de produção de cultura, de cultura infantil e na interação com outros bebês. Moruzzi e Alonso (2019) visualizam os processos de interação e socialização dos bebês sob uma perspectiva sociológica e percebem que os estudos e pesquisas sobre estes sujeitos se inserem majoritariamente no campo da Psicologia. Neste momento, busca-se evidenciar o modo como os campos da Sociologia e da Educação permitem a compreensão sobre os bebês e as crianças bem pequenas, com vistas às suas atividades e a sua cultura infantil.

\section{Bebês e crianças bem pequenas no debate sobre cultura infantil}

O presente artigo, recorte de uma pesquisa de mestrado, busca discutir a maneira pela qual os bebês e as crianças bem pequenas se encontram inseridos no debate acadêmico sobre a cultura infantil. Foram revisados quatorze artigos produzidos nos últimos vinte anos (19992019), selecionados do levantamento realizado para uma pesquisa de mestrado que vem sendo desenvolvida junto a um programa de Pós-Graduação em Educação ${ }^{\text {vi }}$, a qual tem por objetivo mapear o campo da Sociologia da Infância no Brasil e o conceito de cultura infantil em suas publicações. O levantamento geral que é objeto de análise na referida pesquisa foi realizado na base de dados Scielo e Google Acadêmico, com filtro em revistas da área educacional e sociológica, utilizando como descritores de busca as expressões: cultura infantil, culturas

Revista Interinstitucional Artes de Educar. Rio de Janeiro, V. 6, N.2-pág. 653-675 maio-agosto de 2020: "Bebês e crianças: cultura, linguagem e políticas"

DOI: $10.12957 /$ riae.2020.45966 


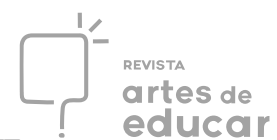

infantis e culturas da infância. O levantamento que é objeto desta pesquisa é analisado sob inspiração cartográfica (PASSOS; KASTRUP; ESCÓSSIA, 2015).

Por se tratar de uma pesquisa de inspiração cartográfica ${ }^{\text {vii }}$, o mapeamento pretendido buscou inverter algumas lógicas, percorrendo um caminho contrário ao que comumente se faz nas pesquisas científicas. Dessa forma, lançou-se mão de um recorte específico tal como "bebês e crianças bem pequenas", buscando identificar de que modo eles estão sendo trabalhados e de que modo se integram à abordagem proposta, qual seja, a cultura infantil. Neste caso, o interesse pelos bebês e pelas crianças pequeninhas demonstrou-se proeminente à esta proposta temática que toma os bebês, suas linguagens e sua cultura elucidativos, integrando diferentes áreas do conhecimento e abordagens de pesquisa, apontando os desafios, as conquistas e os múltiplos olhares e possibilidades para o reconhecimento e agência que bebês e crianças pequenas têm provocado no interior dos estudos teóricos e das práticas sociais. Assim, o mapeamento sobre os bebês e as crianças bem pequenas é apresentado neste artigo a partir de um lugar e contorno específico sobre a infância, resultando no recorte apresentado. O quadro abaixo quantifica as produções analisados por área e ano de publicação:

QUADRO 1. Áreas e ano de publicação dos artigos selecionados para levantamento

\begin{tabular}{|l|l|l|l|l|l|l|l|l|l|}
\hline Área\Ano & 1999 & 2006 & 2008 & 2009 & 2010 & 2011 & 2014 & 2015 & 2019 \\
\hline Educação & 1 & 2 & 2 & 1 & & 1 & 2 & 2 & 1 \\
\hline $\begin{array}{l}\text { Ciências } \\
\text { Sociais }\end{array}$ & & 1 & & & 1 & & & & \\
\hline
\end{tabular}

Fonte: autoras. Dados da pesquisa.

Percebe-se que as publicações, no decorrer dos anos, não são crescentes, mas são constantes no que diz respeito à especificidade dos bebês e das crianças bem pequenas ${ }^{\text {ix }}$. Observa-se também que o maior número de publicações é da área da educação, em revistas de pesquisas e práticas educacionais. Revistas da área sociológica possuem um menor número de publicações com esta temática.

$\mathrm{O}$ artigo "Criança pequenininhas produzem cultura? Considerações sobre educação e cultura infantil em creche”, de Patrícia Dias Prado, parece ser o primeiro que faz referência à dimensão cultural atribuída às crianças menores de três anos de idade. Dialogando, ao mesmo tempo que contrapondo-se à Psicologia, Prado (1999) realiza uma conceituação das crianças de 0

Revista Interinstitucional Artes de Educar. Rio de Janeiro, V. 6, N.2- pág. 653-675 maio-agosto de 2020: "Bebês e crianças: cultura, linguagem e políticas" 
a 3 anos em creches e pré-escolas, com lócus de investigação em uma creche da cidade de Campinas, São Paulo, na qual notou-se que muitas das brincadeiras que observava eram recriadas, reelaboradas e ressignificadas pelas crianças.

Prado (1999) concebe as crianças pequeninhas - utilizando o termo pequenininhas não para inferiorizá-las, mas para demarcar sua diferença e especificidade em relação às crianças maiores e aos adultos - como sujeitos que se apropriam e constroem cultura ao brincarem e interagirem com outras crianças nos espaços de creche. A interação com o outro é a característica que marca a produção de cultura pelo ser humano. Dessa forma, reconhece-se que as crianças não se limitam somente a se apropriar de uma parcela da vida experimentada ou observada dentro e fora das creches, mas que também cuidam de alargá-la, condensá-la, intensificá-la e conduzi-la para novos caminhos.

As crianças pequeninhas aprendem brincando e ensinam outras crianças e adultos por meio de suas brincadeiras. A diferença das crianças pequeninhas em relação ao modo como adultos ensinam outros adultos está na não fala, ou seja, no silêncio com que ocorre esta atividade de atribuir significado e sentido ao mundo em que se vive. A não fala da criança pequena é vista, numa perspectiva psicológica, como incapacidade e dissociação entre a criança e os elementos culturais produzidos pelos adultos. Prado (1999), ao introduzir os bebês e crianças pequeninhas em vias de cultura, quebra com concepções que desvinculam estas crianças das relações sociais e/ou processos de socialização, compreendidos, em geral, como processos de adaptação. A brincadeira aparece, nesta medida, como unidade que produz e veicula projetos de vida humana, neste caso, os projetos de vida das próprias crianças.

$\mathrm{O}$ artigo "Culturas infantis, tensões e negociações entre adultos e crianças numa creche domiciliar", publicado em 2006 por Ana Cristina Coll Delgado apresenta os resultados de uma pesquisa realizada numa creche domiciliar do bairro de São Gonçalo, no Rio de Janeiro. A pesquisadora concebe as crianças como sujeitos ativos e produtoras de cultura. Seu objetivo é analisar os significados do trabalho de tomar conta de crianças num contexto de creche domiciliar, distinto do contexto escolar em seus pressupostos e intencionalidades pedagógicas. Delgado (2006) busca observar o modo como as crianças utilizam os espaços, como criam e realizam atividades e de que modo suas dificuldades são negociadas com os adultos e com as outras crianças que também frequentam estes espaços.

Apesar de ser denominado como creche, o espaço pesquisado por Delgado (2006) não atende apenas crianças de 0-3 anos. Pode-se dizer que os bebês são estudados e retratados no 
artigo em questão de forma indireta, na medida que são considerados balizadores das atitudes das crianças maiores em relação as dimensões da afetividade e dos cuidados com o corpo. Os bebês estão inseridos na cultura da creche domiciliar de que fazem parte na interação que estabelecem com outras crianças, principalmente com as crianças maiores, que aprendem com eles situações a respeito das trocas de fralda. As crianças maiores conversam com os bebês, brincam e colaboram nos cuidados que lhes são dirigidos, inserindo-os numa dinâmica social e cultural de cuidado e educação.

O artigo de Lopes e Vasconcellos (2006) permite que se compreenda o lugar das crianças e das crianças pequenas na construção da infância e dos artefatos culturais. Em "Geografia da infância: territorialidades infantis”, objetivam situar a Geografia da Infância nos estudos da infância, compreendo-a como possibilidade de pluralizar a experiência das crianças em relação aos espaços e aos tempos históricos. Para eles, a infância é construída de acordo com o local em que está situada, ao território a que pertence e ao lugar que a criança ocupa no mesmo. Dessa forma, os conceitos de espaço, território e lugar agregam o conceito de cultura em detrimento da concepção de infância que se coloca em debate.

Os autores demarcam a horizontalidade das crianças entre si e a verticalidade mantida entre estas e os adultos com que se relacionam. Com base em pesquisa de campo os autores observam que as brincadeiras e as relações que as crianças produzem estão intimamente relacionadas ao espaço e ao território que habitam. Dessa forma, ao produzirem brincadeiras e outras relações, as crianças produzem um determinado tipo de infância e com isso balizam os sentidos e os sentimentos que se dirigem à elas Os espaços, nessa medida, são determinados e determinantes das brincadeiras das crianças, de acordo com os valores que lhes são atribuídos e as experiência que pode proporcionar a uma criança ou grupos de crianças.

Lopes e Vasconcellos (2006) consideram a produção de cultura pelas crianças, inclusive pelas crianças pequenas, que desde o nascimento são inseridas em contextos de tradição e de rituais que se relacionam diretamente com o lugar em que habitam. Os autores consideram que os sujeitos vivem, desde que nascem, em redes de significados nos quais incorporam dimensões dos espaços e dos territórios a que pertencem.

Ao mencionarem a inserção da criança bem pequena na cultura, Lopes e Vasconcellos (2006) consideram a inevitabilidade de serem atingidas pela organização social adulta. Neste caso, desde a concepção, incluindo a gestação e o posterior nascimento, as crianças estão inseridas na cultura, participam de rituais e de tradições que envolvem as dimensões da fala, do

Revista Interinstitucional Artes de Educar. Rio de Janeiro, V. 6, N.2- pág. 653-675 maio-agosto de 2020: "Bebês e crianças: cultura, linguagem e políticas" 
caminhar e inclusive das características fisiológicas das mesmas, baseadas nas tradições e simbolismos de um determinado grupo.

Em "Pequena infância, educação e gênero: subsídios para um estado da arte”, Faria (2006) compreende o espaço da creche e da pré-escola, modalidades da Educação Infantil, como cultural em sua origem, historicidade e consolidação que se interpõe à luta feminista das mães trabalhadoras que reivindicavam, por volta dos anos de 1970, por espaços de cuidado e educação para as crianças.

A autora abarca questões de gênero na problemática de seu texto, compreendendo a Educação Infantil como espaço de expressão das crianças pequenas e também das crianças mais pequenas, referindo-se aos bebês. Faria (2006) menciona o fato de que historicamente e por tantas áreas do conhecimento a criança foi considerada um vir-a-ser, um cidadão incompleto nas palavras de Walter Benjamin, compreendida por um viés psicologizante, patológico e higienista. A autora apresenta uma sequência de fotos em que a bebê Laura demonstra seu modo de pensar e de construir cultura.

Ao realizar o balanço das pesquisas na área educacional a respeito das crianças pequenas, Faria (2006) compreende que se tem elucidado uma criança que é portadora de história, capaz de múltiplas relações, produtora de culturas infantis e sujeito de direitos. Ainda assim, a autora percebe uma lacuna no que se refere às pesquisas e práticas realizadas com as crianças bem pequenas como Laura, aquelas que não falam, não andam e não leem, mas que se comunicam de outras formas. A estas pesquisas e práticas, Faria (2006) indica a necessidade da escuta, das relações e da consideração da diferença.

Jader Janer Moreira Lopes é autor do artigo "Geografia das Crianças, Geografia das Infâncias: as contribuições da Geografia para os estudos das crianças e suas infâncias" e contribui para os estudos das infâncias no sentido de atribuir significado ao lugar e ao tempo que as crianças ocupam na sociedade, aos territórios e aos espaços em que se inserem. Lopes (2008) agrega às crianças a potencialidade da infância e da produção de diferentes arranjos culturais e traços simbólicos ao pertencerem a grupos sociais. O espaço é considerado indicativo de negociação entre as crianças e os adultos, implicando a produção de culturas. Na primeira parte do texto, o autor expõe a problemática que os estudos sobre a infância, ao se introduzirem numa perspectiva de negatividade, impuseram à criança o não-lugar, a não-fala, a não-razão e o nãotrabalho e o não-tempo, portanto, a criança desconsiderada em sua singularidade, desconhecendo seu papel de sujeito social e suas possibilidades de construção cultural.

Revista Interinstitucional Artes de Educar. Rio de Janeiro, V. 6, N.2- pág. 653-675 maio-agosto de 2020: "Bebês e crianças: cultura, linguagem e políticas" 
Com referência a Sarmento (2005), Lopes (2008) considera a possibilidade de os bebês se comunicarem e se expressarem mesmo que não falem, retirando a criança do lugar da nãofala, da negatividade, portanto. As crianças e as crianças pequenas produzem cultura e negociam suas existências com as demais categorias presentes na sociedade, negando a condição de categoria inferior em que foram histórica e geograficamente construídas.

$\mathrm{O}$ artigo "Práticas de socialização entre adultos e crianças, e estas entre si, no interior da creche", escrito por Altino José Martins Filho, tem por objetivo descrever, analisar e interpretar as dinâmicas das relações entre adultos e crianças em espaços de creche. Por creche, o autor compreende as instituições de Educação Infantil que recebem crianças de 0 a 6 anos. Ao diferenciar as atitudes e atividades das crianças daquelas realizadas pelos adultos, Martins Filho (2008) demarca a diferença entre esses sujeitos e garante que a singularidade da infância resida num contexto demarcado pela ação das crianças - caracterizadas pelo autor como culturas infantis. Culturas infantis são as representações simbólicas a respeito do mundo com o qual as crianças interagem; são também as regras e estratégias, os modos de apreensão desse mundo, os estilos de vida das crianças. Ao incluir até mesmo as crianças pequeninhas nesta conceituação de culturas infantis, Martins Filho (2008) garante que se visualize que estas resistem, reagem, subvertem e até mesmo transgridem a lógica do adulto. O pesquisador verificou que as crianças transgrediam, por exemplo, "a hora do sono". Resistindo a imposição dos adultos sobre os momentos e horários de dormir, as crianças comunicavam-se por meio de gestos e olhares, escondiam brinquedos e tocando os pés uns dos outros, construíam uma lógica de comunicação que lhes era própria.

"Quietas e caladas: as atividades de movimento com as crianças na Educação Infantil”,, de Iza e Mello (2009) é resultado de uma investigação realizada em uma Centro Municipal de Educação Infantil de uma cidade do interior paulista. O foco da investigação foi observar e analisar atividades de movimento das crianças na Educação Infantil e os tipos de mediações realizadas pelas professoras.

Iza e Mello (2009) trazem exemplos do modo como as crianças pequenas realizam atividades para além daquelas estipuladas e planejadas pelas professoras. Uma situação é interessante de ser destacada, a qual um rádio com música é colocado na sala e as crianças instantaneamente se organizam em roda esperando por alguma atividade. As professoras não solicitaram ou mediaram a situação para que as crianças se colocassem da forma como foram

Revista Interinstitucional Artes de Educar. Rio de Janeiro, V. 6, N.2- pág. 653-675 maio-agosto de 2020: "Bebês e crianças: cultura, linguagem e políticas" 
observadas, mas o fizeram com base em experiências anteriores, em que roda e música se relacionam com determinadas práticas pedagógicas.

As autoras destacam também o modo como as atividades de movimento são desconsideradas para as crianças de 4 meses a 2 anos em razão das demandas de higiene, alimentação e descanso, neste caso, atividades caracterizadas por Iza e Mello (2009) como de cuidados essenciais: higiene e alimentação. O modo como as próprias professoras organizavam os ambientes educativos e as salas de atividades coletivas dificultavam o trabalho pedagógico, no sentido de associar o cuidado e a educação ${ }^{\mathrm{x}}$.Verificou-se, por exemplo, que os brinquedos que deveriam estar dispostos às crianças estavam guardados em armários longe do alcance das mesmas. Apesar disso, as autoras observam que as crianças se movimentam pelo espaço mesmo que sem mediação de suas professoras, expressando seus sentimentos por meio de seus movimentos. O movimento dos bebês e das crianças pequenas são considerados meios de comunicação das mesmas.

O artigo de Flávia Pires intitulado “O que as crianças podem fazer pela antropologia?” é de grande relevância para este estudo. Ao reconhecer as crianças como seres sociais, dotados de agência histórica, social e cultural e atravessadas por forças que ultrapassam a passividade, a antropologia garante que sejam compreendidas pela produção e pela intervenção na dinâmica social.

Duas concepções diferentes sobre os processos de socialização são colocadas em debate por Pires (2010). A autora indica, primeiramente, uma concepção de socialização que considera a criança como índice. Nesta perspectiva, as crianças, incluindo os bebês, são seres associais que se tornam sociais na medida em que os valores e padrões de uma determinada sociedade lhes vão sendo inculcados. O conhecimento, nesta perspectiva, é aquele que se passa dos adultos para as crianças de forma passiva, caracterizando um mecanismo gradativo de obtenção de cultura, no qual o conceito socialização vai sendo assemelhado à domesticação. É nesta medida que, com referência a Toren (1999), trabalha-se contra a ideia de que os bebês são tábulas rasas nas quais se imprime, de forma descorporificada e abstrata, os valores de uma sociedade.

Por outro lado, Pires (2010) corrobora com uma concepção de socialização que considera as crianças como agentes. Nesta perspectiva, os sujeitos são reconhecidos como autopoiéticos, ou seja, produzidos de maneira única e singular, em que não se reconhece a cultura pela estaticidade, mas pela mutabilidade, pela troca e pelas relações estabelecidas. Abordagens que tratam as crianças como agentes sociais, produtores de cultura e personagens históricos são 
levadas em conta na medida em que se reconhece que não há um roteiro para a vida social e cultural, revelando a dinamicidade deste processo.

Os contributos deste artigo para a contextualização de uma cultura que é apreendida e transformada também pelas crianças bem pequenas, no caso os bebês, estão na compreensão de que a socialização e a produção e reprodução de cultura são processos dinâmicos e complexos, não estáticos, pelas quais estes sujeitos aprendem mas também ensinam, intencionalmente ou não, a ação dos adultos em relação à eles.

Costa e Gontijo (2011) reconhecem as crianças como sujeitos produtores de linguagem. No artigo intitulado "A linguagem oral como elemento integrante da brincadeira”, resultado de uma investigação realizada numa instituição de Educação Infantil que atendia crianças de 2 a 6 anos de idade, as autoras percebem que a linguagem, elemento integrante das brincadeiras e dos jogos infantis, era comumente criada e recriada pelas crianças. $\mathrm{O}$ artigo permite, ao sinalizar o papel da linguagem na dimensão cultural, compreender o modo como estes sujeitos estão inseridos em dinâmicas de expressão e comunicação desde que nascem, nas interações que estabelecem com os adultos e nas suas vivências diárias.

Costa e Gontijo (2011) percebem que além de ocupar determinadas posições sociais, assumindo papeis e protagonizando situações da vida real, as crianças fazem uso da linguagem criando-a e recriando-a - para demarcar os lugares que ocupam nas brincadeiras. A brincadeira é compreendida em sua dimensão de inserção da criança na atividade humana, possibilitando sua penetração no mundo dos adultos. A linguagem é tida como este elemento cultural que permeia as relações sociais de que as crianças fazem parte, compreendida como elemento capaz de organizar e compartilhar a brincadeira. Costa e Gontijo (2011) afirmam o modo pelo qual as crianças fazem uso da linguagem - e de todos os seus elementos discursivos, incluindo os textos que produzem, os enunciados que reproduzem e os gêneros que compreendem.

No artigo "A criança, as culturas infantis e o amplo sentido do termo brincadeira” Spréa e Garanhani (2014) realizam um diálogo intrigante entre a proposta do sociólogo Florestan Fernandes com a teoria histórico-cultural de Vygotsky. O objetivo expresso no texto é contextualizar o modo como se dá a atividade de brincar pelas crianças, reconhecendo-a pela dimensão da produção cultural. Os autores reconhecem que as crianças não apenas reproduzem os elementos, disposições e sinalizações da cultura adulta, mas o fazem a partir de seus próprios referenciais, produzindo novas formas de estar e de se relacionar com seus pares a partir de determinadas imposições. Uma vez assimétrica a relação que as crianças estabelecem com os 
adultos, nos grupos infantis as crianças se veem na possibilidade de estabelecer relações mais horizontais entre si.

Spréa e Garanhani (2014) informam que as convenções, parâmetros e regras da vida social adulta é assimilada e exercida pela criança, ao passo em que são questionadas e adaptadas com base em seus próprios interesses. O brincar é compreendido como atividade na qual as crianças vão realizar estas assimilações e construir suas próprias regras para colocá-las em prática. Com base em Fernandes (2004), os autores caracterizam as brincadeiras tradicionais como todas aquelas que fazem parte da cultura popular e são carregadas de função social, sinalizando as parlendas e cantigas que são passadas de geração em geração entre os indivíduos de grupos sociais diversos e principalmente entre as crianças em seus grupos.

De modo geral, o artigo não se preocupou em estabelecer conexões com a dimensão culturas das crianças mais pequenas, tampouco com os bebês. Isto não havia ficado explícito com a leitura de seu resumo, mas pode-se perceber ao longo da leitura completa do mesmo.

"Culturas infantis: contribuições e reflexões", escrito por Maria Carmen Silveira Barbosa, é de grande contribuição para a discussão aqui a respeito da cultura. O esforço das áreas que compõe os Estudos Sociais da Infância em compreender infância no plural, portanto, infâncias, é reconhecido por Barbosa (2014). Numa concepção que reconhece o plural da cultura, a dinâmica não é estática, mas dependente da atividade humana, inclusive da atividade das crianças. Barbosa (2014) responde a sua primeira pergunta "As crianças pequenas produzem cultura?", enfatizando o modo como estes sujeitos se relacionam com os objetos e pessoas de um determinado espaço de forma simbólica, dinâmica e interativa, nas brincadeiras e na própria linguagem. A agência dos bebês e das crianças pequenas é valorizada ao final do texto, quando Barbosa (2014) faz referência a Hanna Arendt (2003) afirmando que o nascimento é sempre a possibilidade de renovação do mundo, evidenciando que a presença de um recém-nascido abre a possibilidade não apenas de uma vida nova, mas também a de recriar o mundo.

Em “Educação Infantil: tempo integral ou educação integral?”, Barbosa, Richter e Delgado (2015) promovem o debate sobre como uma educação integral para bebês e crianças pequenas se distancia e por vezes se contrapõem à um projeto de educação em tempo integral para estes sujeitos. As autoras realizam a diferenciação entre bebês e crianças pequenas ao longo de todo o texto e é nesta medida que colaboram para a enunciação e a valorização destes sujeitos em espaços educativos: considerando-os produtores de culturas, agentes de mudança social e de transformação. 
Barbosa, Richter e Delgado (2015) iniciam realizando a crítica sobre o modo como a Educação Infantil de tempo integral vem se demonstrando como único modo de educação dos bebês e das crianças pequenas em espaços institucionalizados. Com base em três pontos centrais as autoras desenvolvem a ideia de que uma educação integral solicita a ação integral não só dos atores das instituições de Educação Infantil, mas de diferentes atores sociais, tais como as famílias, a comunidade e sujeitos de outros espaços que interagem diretamente com a educação das crianças pequenas, tais como os da saúde, da proteção e da alimentação.

A dicotomia cuidar/educar se demonstra imperativo para a não realização de uma educação integral segundo Barbosa, Richter e Delgado (2015) e é nesta medida que o estudo realizado por elas garante que os bebês sejam percebidos e reconhecidos em suas singularidades. Ao ser compreendida em dois polos separados, sendo eles o cuidar e o educar, a prática com bebês acaba por ser resumida ao primeiro, enquanto às crianças maiores são dirigidas atividades de cunho educativo e pedagógico.

Barbosa, Richter e Delgado (2015) compreendem a cultura como a atividade de agir e estar no mundo, transformando-o desde que os indivíduos o pertencem. A cultura, para elas, não é algo que se possui, mas aquilo que se faz e se refaz. Dessa forma, interpreta-se que os bebês, ao nascerem, transformam o mundo, habitam um mundo já existente e com ele constroem suas próprias histórias.

Barbosa, Richter e Delgado (2015), ao promoverem o pensamento a respeito da integralidade da infância, dos devires e das incompletudes das crianças, invocam outros meios para se pensar a educação e o cuidado dos bebês e das crianças pequenas, meios que as reconheçam, que as singularizem, que as permitam expressar como podem e que invoca aos professores e professoras da Educação Infantil outros meios também de interpretação.

"Gritos sem palavras: resistências das crianças pequenininhas negras frente ao racismo”, de Flávio Santiago, sinaliza o modo pelo qual as instituições de Educação Infantil são atravessadas por situações de racismo estrutural e como a subjetividade das crianças pequenininhas vai sendo construída nas rotinas e práticas pedagógicas. Santiago (2016) busca compreender de que modo as culturas infantis são construídas no interior da violência do processo de racialização.

Ao acompanhar um grupo de crianças pequenininhas com idade de 3 anos, Santiago (2016) percebe que as relações, assim como as situações cotidianas, desses sujeitos com os adultos que as educam são perpassadas por relações de poder e por determinações de 2020: "Bebês e crianças: cultura, linguagem e políticas" 
adultrocêntricas que se fortalecem em práticas de discriminação e racismo. O artigo em questão apresenta as impressões do autor no que tange ao modo como as crianças pequeninhas produzem culturas em seus grupos, resistindo às imposições adultas e às lógicas normatizadoras que as cerceiam. As ações docentes são evidenciadas no que diz respeito às falas e silenciamentos em relação a situações de racismo com as crianças e destas entre elas.

Para Santiago (2016), a colonização dos modos de ser e de viver dos adultos sobre as crianças impede-lhes que sejam percebidas em potencialidade e agência. $\mathrm{O}$ choro, os gritos, o desânimo, as mordidas e as "bagunças" das crianças bem pequenas são compreendidas por ele como linguagens que invocam uma vida que lhes seja própria. As crianças gritam sem palavras e esse grito, particular a elas, é reconhecido como linguagem. A linguagem das crianças demonstra-se imperativo para a produção de suas culturas e incorporam a suas atitudes de resistência a possibilidade de transformar as relações e os espaços que fazem parte, mostrando aquilo que sentem e aquilo que não desejam.

Ao realizar uma investigação com vinte e cinco crianças bem pequenas de uma instituição de Educação Infantil, Campos e Gomes (2019) reconhecem as brincadeiras como motivadoras das relações entre elas e como mote para a produção de suas culturas. No artigo intitulado "Participação social de crianças em brincadeiras: aproximações às culturas da infância na educação infantil”, percebem o modo como as crianças da turma investigada produziam e reproduziam situações de amizade para conquistar ou mesmo sinalizar interesses particulares. Expressões como "Você é meu amigo" e "Eu sou seu amigo" são caracterizadas como própria das crianças que se interessam por objetos ou brinquedos específicos e elaboram estratégias para tê-los.

Outro episódio destacado pelas autoras faz referência ao modo como as brincadeiras das crianças são permeadas por experiências e vivências derivadas das suas interações com adultos, dentro ou fora do espaço escolar, com exemplo da própria família. O conteúdo dessas brincadeiras que envolvem situações familiares demonstrou o modo como as crianças aceitam ou negam determinadas situações e elaboram estratégias para negociar suas entradas nas brincadeiras produzidas por outras crianças. Campos e Gomes (2019) reconhecem, com base em Cohn (2005), que a cultura produzida pelas crianças não está nos artefatos ou nas frases das crianças, mas na simbologia das relações sociais que as conformam ou lhes dão sentido.

O artigo em questão não é específico da educação e socialização de bebês, mas permite o olhar para a pequena infância e para as crianças bem pequenas no sentido de reconhecê-las como 
portadoras de uma maneira específica de ser e estar no mundo: pela brincadeira. O brincar, segundo Campos e Gomes (2019), é a forma privilegiada de as crianças participarem da cultura.

\section{Delineando algumas considerações}

Este artigo buscou compreender de que modo os bebês e as crianças bem pequenas estão inseridos no debate acadêmico sobre cultura infantil, indicando, ainda que de modo geral, o que as pesquisas discorrem, se discorrem e como discorrem sobre esses sujeitos.

Os bebês aparecem nas pesquisas analisadas aproximados às crianças bem pequenas. De modo mais específico, as pesquisas sobre cultura infantil compreendem a ação destes sujeitos no mundo, considerando-os potentes ao fazerem uso de diferentes linguagens e ao produzirem cultura nos em contextos de comunicação, relação e produção cultural, em espaços coletivos de cuidado e educação. As pesquisas sobre cultura infantil que mencionam os bebês e as crianças pequeninhas têm considerado suas diferentes linguagens que por meio das quais eles se comunicam, se expressam, aprendem e descobrem o mundo. Ao analisar artigos das áreas da Educação e das Ciências Sociais, leva-se em consideração que os bebês estão inseridos na cultura ao passo que produzem uma cultura que lhes é própria, culturas estas que estão relacionadas às suas territorialidades, materialidades e outros sujeitos com que se relacionam, sejam estes outros bebês e outras crianças e até mesmo adultos.

Este artigo reconhece que as crianças possuem muitas linguagens e com elas se comunicam, inventam o mundo, descobrem a natureza, descobrem as outras crianças, percebem o social e fazem parte da cultura. Assim como a mulher, os negros, os indígenas e tantas outras minorias, as crianças são subalternas, são colocadas a margem e são feitas reféns de uma cultura que pouco ou nada lhes diz respeito. As crianças são lidas pela lente do machismo, do patriarcado e do adultocentrismo e deixam de ser escutadas e interpretadas na especificidade que lhes garante o direito de serem crianças. A criança é subalternizada por ser vinculada ao modo de ser dos adultos. As crianças não são vistas, porque ao adulto não interessa enxergá-las, não são ouvidas, pois seus gritos ensurdecem a dinâmica avassaladora em que estes vivem. "Penso, logo conquisto", era isso que Descartes queria dizer. Se sou dotado da razão e do potencial de fala, conquisto e minha conquista se dá em detrimento da inferiorização do outro. As categorias de mulher e de criança são construídas social e culturalmente junto ao pilar da invisibilidade, da falta, da minoria e da subalternidade.

Revista Interinstitucional Artes de Educar. Rio de Janeiro, V. 6, N.2- pág. 653-675 maio-agosto de 2020: "Bebês e crianças: cultura, linguagem e políticas" 
Este artigo buscou olhar para a criança como o outro, o outro que existe, que habita a infância, que se encontra na diferença das relações, das interpretações e das linguagens que utiliza para se comunicar e para produzir cultura. O que fazem os bebês e as crianças bem pequenas, nos interditos de suas existências, é o que os tornam especiais, particulares. Buscou-se, portanto, mostrar que os bebês e as crianças bem pequenas possuem cultura - assim como as crianças maiores e os adultos -, se expressam, falam, gritam, chorar, brincam, trocam, interagem, se relacionam e com isso, fazem parte do mundo, esse mundo que é delas e que é feito por elas, todos os dias, nos seus grupos, nas suas individualidades, nas suas especificidades e nas suas culturas.

Se a infância é uma construção social, é possível reconhecer as outras infâncias - a infância dos bebês e das crianças bem pequenas - não apenas no sentido de construir, mas de pensar, garantir, proteger, valorizar, investir e escutar estas infâncias. Falamos, tal como Qvortrup (2010), de infância como uma categoria geracional e estrutural. Mais do que compreender que as crianças habitam essa categoria geracional chamada infância, reforçamos o modo como estruturam essa infância a partir de suas diferenças, de suas particularidades e de suas formas de construir conhecimento sobre a sociedade.

Há infâncias sendo vividas e experimentadas pelos bebês e pelas crianças pequeninhas, protagonizadas em suas ações, em suas produções e em suas linguagens e as pesquisas explicitam que eles o fazem por vias da ação, da reação, da resistência e da positividade. Os estudos pós-coloniais permitem a compreensão de que há outras formas de olhar para estes sujeitos e é nesta medida que a Educação Infantil, no sentido de espaço da e para a infância, deve valorizar a criança, suas culturas, suas especificidades e seus direitos. Novas epistemologias se tornam emergentes, neste caso, uma epistemologia da educação e da socialização que leve em conta os bebês e as crianças bem pequenas, que as escutem, que façam uso de outras metodologias de investigação e que sejam capazes de captar as vozes que ressoam, que ecoam e que invocam outros olhares, outras lentes e outras formas de os adultos as visualizarem. A expressão "Domino, logo existo", invoca ser desconstruída.

\section{REFERÊNCIAS}

ABRAMOWICZ, Anete; OLIVEIRA, Fabiana. A Sociologia da Infância no Brasil: uma área em construção. Educação, v. 35, n. 1, p. 39-52, 2010.

Revista Interinstitucional Artes de Educar. Rio de Janeiro, V. 6, N.2- pág. 653-675 maio-agosto de 2020: "Bebês e crianças: cultura, linguagem e políticas" 
ABRAMOWICZ, Anete (org.). Estudos da Infância no Brasil: encontros e memórias. São Carlos: EdUFSCar, 2015.

ABRAMOWICZ, Anete; LEVCOVITZ, Diana; RODRIGUES, Tatiane Cosentino. Infâncias em Educação Infantil. Pro-Posições, Campinas, v. 20, n. 3, p. 179-197, 2009.

ARIÈS, Phillippe. A história Social da criança e da família. Rio de Janeiro: Zahar, 1982, p. $17-32$.

BADINTER, Elisabeth. Um amor conquistado: o mito do amor materno. Tradução de Waltensir Dutra. Rio de Janeiro: Nova Fronteira, 1985.

BARBOSA, Maria Carmen Silveira. Culturas infantis: contribuições e reflexões. Rev. Diálogo Educ., v. 14, n. 43, p. 645-667, 2014.

BARBOSA, Maria Carmen Silveira; RICHTER, Sandra Regina Simonis; DELGADO, Ana Cristina Coll. Educação Infantil: tempo integral ou educação integral? Educação em Revista, v. 31, n. 04, p. 95-119, 2015.

BRASIL. Prática cotidianas na Educação Infantil: bases para a reflexão sobre as orientações curricualares. Ministério da Educação, Secretaria de Educação Básica, Universidade Federal do Rio Grande do Sul, 2009.

CAMPOS, Rafaely Karolynne do Nascimento; RAMOS, Tacyana Karla Gomes. Participação social de crianças em brincadeiras: aproximações às culturas da infância na educação infantil. Zero a seis, v. 21, n. 38, p. 51-66, 2019.

COHN, Clarice. Antropologia da Criança. Rio de Janeiro: Editora Jorge Zahar, 2005.

COSTA, Dânia Monteiro Vieira; GONTIJO, Cláudia Maria Mendes. A linguagem oral como elemento integrante da brincadeira. Cadernos de Pesquisa, v. 41, n. 142, 2011, p. 268-289.

DELEUZE, Gilles.; GUATTARI, Félix. Mil platôs: capitalismo e esquizofrenia, v. 1. Rio de Janeiro: Editora 34, 1995.

DELGADO, Ana Cristina Coll. Culturas infantis, tensões e negociações entre adultos e crianças numa creche domiciliar. Currículo sem Fronteiras, v. 6, n. 1, p. 82-102, 2006.

DESCARTES, René. Meditações. (Os Pensadores) São Paulo: Abril Cultural, 1983.

FARIA, Ana Lúcia Goulart de. Pequena infância, educação e gênero: subsídios para um estado da arte. Cadernos pagu, 2006, P. 279-287.

FERNANDES, Florestan. As "Trocinhas" do Bom Retiro: Contribuição ao Estudo Folclórico e Sociológico da Cultura e dos Grupos Infantis. Pró-Posições, v.15, n. 1, 2004

Revista Interinstitucional Artes de Educar. Rio de Janeiro, V. 6, N.2- pág. 653-675 maio-agosto de 2020: "Bebês e crianças: cultura, linguagem e políticas" 
GOBBATO, Carolina; BARBOSA, Maria Carmen Silveira. A (dupla) invisibilidade dos bebês e das crianças bem pequenas na educação infantil: tão perto, tão longe. Revista Humanidades e Inovação, v. 4, n. 1, 2017, p. 21-36

GUATTARI, Félix. As creches e a iniciação. In: GUATTARI, Félix. Revolução Molecular: pulsações do desejo. Brasiliense: Rio de Janeiro, 1985, p. 50-55.

HALL, Stuart. Quando foi o pós-colonial? Pensando no limite. In: HALL, Stuart. Diáspora: identidades e mediações culturais. Belo Horizonte: Editora UFMG, Brasília: representação da UNESCO no Brasil, 2003, p. 101-128.

IZA, Dijnane Fernanda Vedovatto; MELLO, Maria Aparecida. Quietas e caladas: as atividades de movimento com as crianças na Educação Infantil. Educação em Revista, v. 25, n. 02, 2009, p. 283-302.

LOPES, Jader Jane Moreira. As crianças, suas infâncias e suas histórias: mas por onde andam suas geografias? Educ. foco, v. 13, n. 2, p. 31-44, 2009.

LOPES, Jader Janer Moreira. Geografia das Crianças, Geografia das Infâncias: as contribuições da Geografia para os estudos das crianças e suas infâncias. Contexto e Educação, ano 23 , n. 79, 2008, p. 65-82.

LOPES, Jader Janer Moreira; VASCONCELLOS, Tânia de. Geografia da infância: territorialidades infantis. Currículo sem Fronteiras, v. 6, n. 1, p. 103-127, 2006.

MARTINS FILHO, Altino José. Práticas de socialização entre adultos e crianças, e estas entre si, no interior da creche. Pro-Posições, v. 19, n. 1, 2008, p. 97-114.

MORUZZI, Andrea Braga; ALONSO, Giovana. Os bebês interrogam a infância? Um estudo de bebês sob aportes sociológicos. In: TEBET, Gabriela (Org.). Estudos de bebês e diálogos com a Sociologia. São Carlos: Pedro e João Editores, 2019, p. 519-538.

NASCIMENTO, Maria Letícia B. P. A creche na Educação Infantil: entre o ofício e o direito. Estud. Sociol., Araraquara, v. 15, n. 29, p. 555-566, 2010.

NASCIMENTO, M. L. Algumas considerações sobre a infância e as políticas de educação infantil. Educação e Linguagem, v. 14, n. 23/24, p. 146-159, 2011.

OLIVEIRA-FORMOSINHO, Julia; KISHIMOTO, Tizuko Morchida; PINAZZA, Monica Appezzato. (Orgs). Pedagogia(s) da infância: dialogando com o passado, construindo o futuro. Porto Alegre: Artmed, 2007.

ONOFRE, Márcia Regina; TOMAZETTI, Cleonice Maria; MARTINS, Andressa de Oliveira. Processos Formativos de Professoras de Educação Infantil:olhares sobre a profissão. Revista de Educação Pública , v. 26, p. 729-752, 2017.

Revista Interinstitucional Artes de Educar. Rio de Janeiro, V. 6, N.2- pág. 653-675 maio-agosto de 2020: "Bebês e crianças: cultura, linguagem e politicas" 
PASSOS, Eduardo; KASTRUP, Virgínia; ESCÓSSIA, Liliana (Orgs.). Pistas do método da cartografia: pesquisa-intervenção e produção de subjetividade. Porto Alegre: Sulina, 2015.

PIRES, Flávia. O que as crianças podem fazer pela antropologia? Horizontes antropológicos, ano 16, n. 34, p. 137-157, 2010.

PRADO, Patrícia Dias. As crianças pequenininhas produzem cultura? Considerações sobre educação e cultura infantil em creche. Pro-Posições, v. 10, n. 1, 1999, p. 110-118.

QUINTEIRO, Jucirema. Sobre e emergência de uma sociologia da Infância: contribuições para o debate. Perspectiva, Florianópolis, v. 20, n. Especial, p. 137-162, 2002.

QVORTRUP, Jens. A infância enquanto categoria estrutural. Educação e Pesquisa, v. 36, n. 2, p. 631-643, 2010.

RAFFAINI, Patricia Tavares. As meninas são de pano e os meninos são de chumbo? Cultura material e literatura. Secuencia, edición especial, p. 177-187, 2018.

SANTIAGO, Flávio. Gritos sem palavras: resistências das crianças pequenininhas negras frente ao racismo. Educação em Revista, v. 31, n. 02, p. 129-153, 2016.

SPIVAK, Gayatri Chakravorty. Pode o subalterno falar? Tradução de Sandra Regina Goulart Almeida, Marcos Pereira Feitosa, Andrea Pereira Feitosa. Belo Horizonte: Editora UFMG, 2010.

SPRÉA, Nélio Eduardo; GARANHANI, Marynelma Camargo. A criança, as culturas infantis e o amplo sentido do termo brincadeira. Rev. Diálogo Educ., v. 14, n. 43, p. 717-735, 2014.

TEBET, Gabriela Guarnieri de Campos. Isto não é uma criança! Teorias e métodos para o estudo de bebês nas distintas abordagens da Sociologia da Infância de língua inglesa. 2013. 160 f. Tese (Doutorado em Educação) - Universidade Federal de São Carlos, São Carlos, 2013).

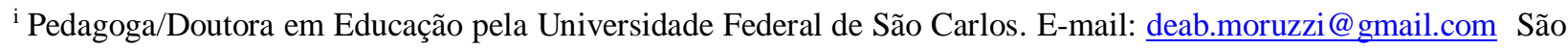
Carlos/ SP. ORCID: https://orcid.org/0000-0001-9406-3915

ii Pedagoga/Mestranda em Educação pela Universidade Federal de São Carlos. E-mail: gyovanaalonso@ hotmail.com. São Carlos/ SP. ORCID: https://orcid.org/0000-0002-3594-2466

iii Compreende-se bebês como crianças de 0 a 18 meses; crianças bem pequenas como aqueles com idade entre 19 meses e 3 anos e 11 meses; crianças pequenas como aquelas entre 4 anos e 6 anos e 11 meses. Reservamos a denominação de crianças maiores para as entre 7 e 12 anos incompletos (BARBOSA, 2009). As nomenclaturas não são utilizadas para fins de classificação ou hierarquização entre as crianças, mas buscam carregar de sentido a especificidade de cada um destes sujeitos. Neste artigo, utilizamos as nomenclaturas bebês e crianças bem pequenas para destacar singularidades e especificidades dos modos de ser desses sujeitos.

iv No Brasil, a Educação Infantil passa a fazer parte do sistema educacional a partir da Lei de Diretrizes e Bases da Educação Nacional (BRASIL, 1996). A Lei 9394/96 é resultado de anos de luta pelo direito à educação dos bebês e das crianças pequenas. Em nosso país, a etapa da Educação Infantil organiza-se em duas modalidades: creches e préescolas, em que a primeira atende as crianças de 0 a 3 anos e a segunda as crianças de 4 a 5 anos.
}

Revista Interinstitucional Artes de Educar. Rio de Janeiro, V. 6, N.2- pág. 653-675 maio-agosto de 2020: "Bebês e crianças: cultura, linguagem e políticas" 


\section{${ }^{v}$ Pedagogia da Infância (OLIVEIRA-FORMOSINHO; KISHIMOTO; PINAZZA, 2007), Antropologia da Criança (COHN, 2005), da Geografia da Infância (LOPES E VASCONCELLOS, 2006; LOPES, 2009), Filosofia da Infância (GUATTARI, 1985) e Historiografia da Infância (ARIÈS, 1982).}

${ }^{v i}$ O levantamento inicial da pesquisa possui 98 produções selecionadas com base nos descritores cultura infantil, culturas infantis e culturas da infância. 23 artigos foram selecionados com o recorte proposto e 14 deles foram considerados proeminentes à proposta deste Dossiê.

vii O método cartográfico ancora-se no conceito de rizoma, expresso em Mil Platôs por Deleuze e Guattari (1995). As cartografias baseiam-se na ideia de rizoma ao considerar processos nos quais os corpos, os discursos e os arranjos se entrelaçam e se emaranham. A cartografia caracteriza a pesquisa científica em termos de multiplicidade dos resultados e possibilidades para sua análise. Assim, ao invés de produzir resultados somente ao final da realização da pesquisa, buscou-se tracejar e elucidar estes resultados durante o seu desenvolvimento. Estes resultados poderiam ter sido produzidos de outra forma - ainda que tivesse sido tomado por referência o mesmo objeto de investigação - caso os objetivos ou os descritores utilizados para análise tivessem sido outros.

viii Inseriram-se na quantificação da área das Ciência Sociais (reconhecendo a denominação do campo de conhecimento e Sociologia como disciplina desta área) duas revistas específicas sobre Antropologia e estudos de gênero.

ix O levantamento realizado não demarcou um recorte temporal, mas sim as áreas temáticas das publicações selecionadas. Portanto, o recorte entre os anos de 1999 e 2019 não é intencional, mas decorrente da seleção realizada com base nos descritores, nas áreas e no objetivo da pesquisa em pauta.

"O termo "cuidado" vem sendo revisado em diferentes perspectivas e estudos, em especial no campo da própria Pedagogia da Infância, sinalizando a não dissociação entre os termos cuidar e educar, em especial nas instituições de atendimento primário à infância, tais como as creches e pré-escolas, considerando que, em toda prática de cuidado à criança, há um sentido educativo e contudo, pedagógico. Ver Onofre, Tomazzetti e Martins (2017). 